\title{
EFFECT OF PERFORATED VERSUS NON-PERFORATED COLLAGEN BARRIER MEMBRANES IN COMBINATION WITH NANO-MICRO- COMPOSITE BONE GRAFTS IN THE REGENERATION OF INTRABONY DEFECTS: A RANDOMIZED CLINICAL TRIAL
}

\author{
Mostafa S. Ashmawy*, Fatma Eldemerdash** and Raghdaa Mostafa*
}

\begin{abstract}
Introduction: Different surgical techniques using combinations of various materials have been utilised to gain predictable regeneration in patients suffering from periodontal disease such as Hydroxyapatite (HA) calcium phosphate (CAP) ceramics through the application of nanotechnology as well as the introduction of a modified perforated membrane (MPM)

Patients and Methods: Five patients (age 25 to 50 years old). Each patient had two contralateral intra-bony defects. Both sides were treated with open flap debridement, followed by the placement of nano hydroxyapatite graft (NanoBone, AtrossGmbH, Germany) mixed with Xenograft (BioOss, Geistlich Pharma North America Inc., 202 Carnegie Center, Princeton, NJ 08540, United States). One side was covered by modified perforated membrane (PM Group), while the other side defect was covered by non-perforated occlusive membrane (OM Group). All patients were referred for immediate postoperative CBCT examination and six month follow up CBCT examination, measurements of bone level changes were performed using fusion module. Data were tabulated and statistically analysed.
\end{abstract}

Results: There was no-statistically significant difference between the two groups in mean plaque index nor in mean gingival index, PM Group showed a statistically significant higher decrease in mean probing depth compared to OM Group, There was non-statistically significant difference between the two groups in mean clinical attachment levels at baseline nor at 6 months.

Conclusion: Our study showed no statistically significant difference between the PM versus the OM regarding defect bone fill at 6 months post-operative duration showing no added benefit for the use of the modified PM regarding the maintenance of bone levels.

\footnotetext{
* Assistant Professor of Oral Radiology, Faculty of Dentistry, Ain-Shams University

** Lecturer of Oral Medicine and Periodontology, Faculty of Dentistry, Misr International University
} 


\section{INTRODUCTION}

Periodontitis was recently defined as a multifactorial inflammatory disease that is associated with dysbiosis within the plaque biofilms and characterized by progressive destruction of the supporting structures of the teeth. Its main features are gingival bleeding, periodontal pocketing, loss of clinical attachment (CAL) and radiographically characterized by alveolar bone loss. It is considered as a major public health problem as it has a high prevalence among the population, a potential cause of tooth loss and masticatory disability and may thus impact the individual's general health. ${ }^{(1)}$

The classification of periodontitis went through repeated modifications in the last 30 years in order to meet with changing scientific evidence. ${ }^{(2)}$ The most recent of which, classified periodontitis as three subcategories: necrotizing periodontitis, periodontitis as a manifestation of systemic disease and the forms that were previously known as "chronic" and "aggressive" are now grouped under the term "periodontitis". ${ }^{(3-8)}$ Furthermore, periodontitis was assigned a multidimensional staging and grading system..$^{(1,3-8)}$

The short term goals of periodontal treatment are the elimination of infection in order to stop the disease progression and prevent its recurrence. This is evident clinically as absence of bleeding on probing and presence of residual shallow pocket depths. ${ }^{(9)}$ On the other hand, the presence of residual deep pocket depths after non-surgical therapy or the use of access flaps often indicates the presence of intrabony defect which may have a negative impact on the prognosis of the involved teeth. ${ }^{(10)}$ In such situations, the healing generally occurs by repair (formation of long junctional epithelium) and none or scarce regeneration (formation of new alveolar bone, cementum and functionally aligned periodontal ligament). ${ }^{(1)}$ This leads to the long term goals of treatment which are the absence of bleeding on probing, shallow pockets with periodontal regeneration. ${ }^{(12)}$
Over the last 50 years, several surgical techniques using combinations of various materials have been utilised aiming to gain predictable regeneration. ${ }^{(13-19)}$ Literature has documented limitations regarding the effectiveness and predictability of various therapies including bone replacement grafts and guided tissue regeneration..$^{(20-23)}$

Different alloplastic grafts have been used with significant improvement in clinical and histological studies. ${ }^{(24,25)}$ Hydroxyapatite (HA) has the advantages of being bioactive, biocompatible, less soluble in moist media, having a high affinity to hard tissues as well as formation of a chemical bond with the host tissue. ${ }^{(26,27)}$ On the other hand, its disadvantages include low rate of resorption, rigidity, brittleness and decreased porosity. ${ }^{(28)}$ Biomaterial research has been focusing on improving the bioreactivity of calcium phosphate (CAP) ceramics through the application of nanotechnology. ${ }^{(29)}$ While micro-sized HA has a small surface area and strong crystal to crystal bond, nano-sized HA have a resorption process similar to bone apatite and provided better outcomes than their micro-sized counterparts due to their bigger surface area to volume ratio as well as their chemical effects. ${ }^{(30-32)}$

Kasaj et al. ${ }^{(33)}$, in a randomized clinical trial, concluded that the use of nano HA paste in the treatment of intrabony defects, provided significant reductions in probing depth (PD) and CAL gains compared to open flap debridement alone both clinically and statistically. Also, Heinz et al. ${ }^{(34)}$ in a similarstudy, indicated that the treatment of intrabony defects with an interdental soft tissue preservation flap and nano HA resulted in improvement in bone gain as well as reduction in PD when compared to papilla preservation flaps alone. Moreover, another study showed that nano HA is capable of triggering the differentiation of periodontal ligament (PDL) cells through a mechanosensitive signalling pathway and expression of bone morphogenic protein- 2 (BMP-2). ${ }^{(35)}$ 
On the downside, the nanosized particles have some unavoidable adverse effects. They tend to adsorb blood proteins forming protein-particle complexes, and can further be phagocytosed by macrophages or fibroblasts and deposit locally in the tissues, resulting in delayed hypersensitivity reactions. They are also capable of dissemination into organs such as the lung, liver and spleen. ${ }^{(37)}$ Nano HA has also been demonstrated in a large percentage of atherosclerotic plaques, and the structural matching of the crystal lattices between cholesterol and HA is assumed to be the cause. ${ }^{(38,39)}$

Some studies suggested that nano HA may have an effect on inhibition of cellular proliferation, ${ }^{(40)}$ while others reported mononuclear cell and fibroblast mortality associated with increasing concentration and duration of nano HA exposure. ${ }^{(41,42)}$ In order to overcome this, a study concluded that the use of a composite graft consisting of nano HA and microsized b-Tricalcium phosphate might improve nano HA retention in periodontal defects. ${ }^{(43)}$

Second to autografts, the closest xenograft to human bone to be regenerated are bovine cancellous grafts, ${ }^{(44)}$ however, they lack biological benefits due to the sterilization processes they go through. (45) Recently, the combination of synthetic materials with xenografts have been suggested both in research and in clinical practice. ${ }^{(46,47)}$ Moreover, studies claim that this new generation of bone grafts called xenohybrid grafts offer better clinical performance, ${ }^{(48)}$ although their osteoinductivity still needs to be investigated. ${ }^{(49)}$

The concept of guided tissue regeneration (GTR) was originally based on the prevention of the downgrowth of the epithelium as well as the exclusion of gingival connective tissue (CT) cells, thus allowing PDL, bone cells and cementoblasts to reach the wound site first. ${ }^{(50)}$

Later studies suggested that gingival mesenchymal stem cells (GMSCs) which exhibit clonogenicity, self-renewal and multipotent differentiation ca- pacities can also contribute to the process of regeneration. ${ }^{(51-54)}$ Gamal and Iacono ${ }^{(55)}$ have compared occlusive guided tissue membranes (OM) using full thickness flap reflection and a modified perforated membrane (MPM) with a dense collar that prevents epithelial downgrowth and a perforated body that permitted gingival CT and its stem cells to reach the wound, showing improved clinical outcomes within the MPM group. They concluded that this may be due to the penetration of stem cells contained within the gingival CT to the periodontal wound area as well as their differentiation into components of the attachment apparatus. ${ }^{(55)}$

The present study was conducted to clinically and radiographically compare the use of perforated and non-perforated collagen barrier membranes combined with nan- hydroxyapatite/xeno composite bone grafts in the periodontal infrabony defects.

\section{PATIENTS AND METHODS}

This study was conducted on five patients recruited from the outpatient clinic of Oral Medicine, Periodontology, Oral Diagnosis and Radiology Department, Faculty of Dentistry, Ain Shams University. All patients were selected to be medically free according to the Cornell Medical Index. ${ }^{(56)}$

The age range was from 25 to 50 years old and they were non-smokers. Each patient had two contralateral intra-bony defects which fulfilled the following criteria: They were characterized as having stage III Periodontitis, ${ }^{(1)}$ probing depth $\geq 5$ $\mathrm{mm}, \mathrm{CAL} \geq 5 \mathrm{~mm}$, as well as a radiographic evidence of vertical bone loss using periapical radiographs. This was a split mouth design, where sites were randomly allocated to receive one of the following interventions.

One side defect was treated with open flap debridement, followed by the placement of nano hydroxyapatite graft (NanoBone, AtrossGmbH, Germany) mixed with Xenograft (Bio-Oss, Geistlich Pharma North America Inc., 202 Carnegie 
Center, Princeton, NJ 08540, United States), covered by modified perforated membrane (PM Group). While the other side defect was treated with open flap debridement, followed by the placement of Nano sized hydroxyapatite graft (NanoBone, AtrossGmbH, Germany) mixed with Xenograft (Bio-Oss, Geistlich Pharma North America Inc., 202 Carnegie Center, Princeton, NJ 08540, United States), covered by non-perforated occlusive membrane (OM Group).

Phase I therapy: consisted of a thorough fullmouth scaling and root surface debridement for all teeth under local anesthesia. This procedure was performed using a combination of hand curets (Gracey curets 1/2 and 7/8, Hu-Friedy, Chicago, IL) and ultrasonic scaler using the P10 tip (Cavitron, long Island City, NY). Patients also received detailed mechanical plaque-control instructions, which consisted of brushing using a soft toothbrush with a roll technique and flossing. Three weeks after initial therapy, a re-evaluation was performed to confirm the need for GTR pocket reconstructive surgery for the selected sites. Membrane perforations were prepared just before surgery using the needle of the syringe, by manually perforating 0.5 - to $1-\mathrm{mm}$ diameter round holes at a distance of $2 \mathrm{~mm}$ from the occlusal edge throughout the length of the barrier membrane. ${ }^{(55)}$

Phase II therapy: The surgical phase consisted of administration of local anesthesia. (Mepecaine L, $2 \%$ kepivacaine HCL, $1.8 \mathrm{ml}$, Alexandria, Company for Pharmaceuticals, Alexandria, Egypt), Patients were then assigned to one of the two treatment groups by the selection of sealed envelopes containing a paper labeled "OM" or "PM." Immediately before surgery, the treating surgeon opened an envelope dictating treatment assignment. OM-selected sites received buccal and lingual/palatal crestal internal bevel incisions starting from the gingival margin to the alveolar crest, exposing all of the gingival CT. For better access to the surgical site, in most cases, the flap was extended one or two teeth mesially or distally. Mucoperiosteal flaps on the facial and lingual/palatal aspects of each involved site were reflected, exposing $2 \mathrm{~mm}$ of the alveolar bone beyond the defect margin. Debridement of all inflammatory granulation tissue from the intrabony defect was performed until a sound, healthy bone surface was observed as well as a smooth root surface. During surgery, the intrabony defect depth and morphology were characterized by recording the number of bony walls. Defects needed to have a minimum depth of $3 \mathrm{~mm}$ (as measured from the most coronal point of the bony walls surrounding the defect to the deepest point in the defect) and presented with two or three bony walls, measuring the defect base level (DBL) as the distance in millimetres from the cementoenamel junction (CEJ) to the base of the defect and the crestal bone level (CBL) as the distance from the CEJ to the alveolar crest.

The intra-bony defects were grafted by placement of Nano sized hydroxyapatite graft ((NanoBone, AtrossGmbH, Germany) ) of an average size $60 \mathrm{~nm}$ mixed with Xenograft (Bio-Oss, Geistlich Pharma North America Inc., 202 Carnegie Center, Princeton, NJ 08540, United States)) of granule size 0.25-1.0 $\mathrm{mm}$. Collagen membranes were hydrated in sterile saline, trimmed according to the template prepared for each defect, and adapted over the defects in such a manner that the entire defect and 2 to $3 \mathrm{~mm}$ of the surrounding alveolar bone was completely covered to avoid membrane collapse within the defect. The membranes (BioMend Extend, Zimmer Dental, Carlsbad, CA) were extended supra-crestally 1 $\mathrm{mm}$ below the CEJ to ensure optimum gingival CT involvement in supra-crestal wound healing. Periosteal releasing incisions were made whenever needed to permit tension-free coronal positioning of the flaps and complete coverage of the membranes. The mucoperiosteal flaps were repositioned to cover the membranes and then stabilized with 3-0 Vicryl sutures (Vicry, Ethicon, Jonson\& Johnson, Somerville, NJ) using an interrupted suturing 
technique. The same procedures were performed for PM-selected sites except for using perforated collagen membranes.

Patients received antibiotics for 1 week (Amoxicillin 500mg 3 /day) (Amoxil MUP, Egypt) and (Metronidazole 250mg 3 / day) (Flagyl Sanofi Aventis, Egypt). They were instructed to rinse twice daily with a $0.12 \%$ chlorhexidine digluconate (Antiseptol Kahira Pharm Egypt) and to avoid mechanical plaque removal at the site of surgery for 15 to 30 days.

The following clinical parameters were scored by a separate operator at baseline and 6 months postoperatively: Plaque Index,${ }^{(57)}$ Gingival Index,${ }^{(57)}$ periodontal probing depth $(\mathrm{PD})^{(58)}$ and clinical attachment level (CAL) $)^{(58)}$

\section{Radiographic Evaluation}

All patients were referred for immediate postoperative CBCT examination at the Oral Radiology Department, Faculty of Dentistry, AinShams University. CBCT was found to be beneficial and accurate in cases of infrabony defects and furcation involvements. ${ }^{(59)}$ The image acquisition was performed using i-CAT next generation (Imaging sciences international, Hatfield, PA, USA) with exposure parameters $120 \mathrm{kVp}, 5 \mathrm{~mA}, 0.2 \mathrm{~mm}$ voxel size, 26 seconds scanning time and field of view was limited to the mandibular arch $(5 \times 10$ $\mathrm{cm}$ ). The radiographic scanning was repeated six months after the surgery using the same parameters.

\section{Image analysis}

The resultant image volumes were saved as DICOM (Digital Imaging and Communication in Medicine) files, then transferred to a third party software OnDemand 3D (Cybermed, Seoul, South Korea) which was used for image manipulation and analysis. Fusion module which allows a voxel based registeration (VBR) was used for accurate standardization of the bone level measurement at each investigated site (Fig. 1).

The immediate postoperative scan was selected as the primary volume and the six-month scan as the secondary volume. Auto registration tool was used to superimpose both volumes. We used the 2 $\mathrm{X} 3$ screen to view only the primary and secondary volumes, as this allowed better visualization and facilitated synchronized scrolling in both the primary and secondary volumes instantly.

On the axial window, at a selected region of interest (ROI), the coronal plane was oriented perpendicular to both buccal and lingual aspects of

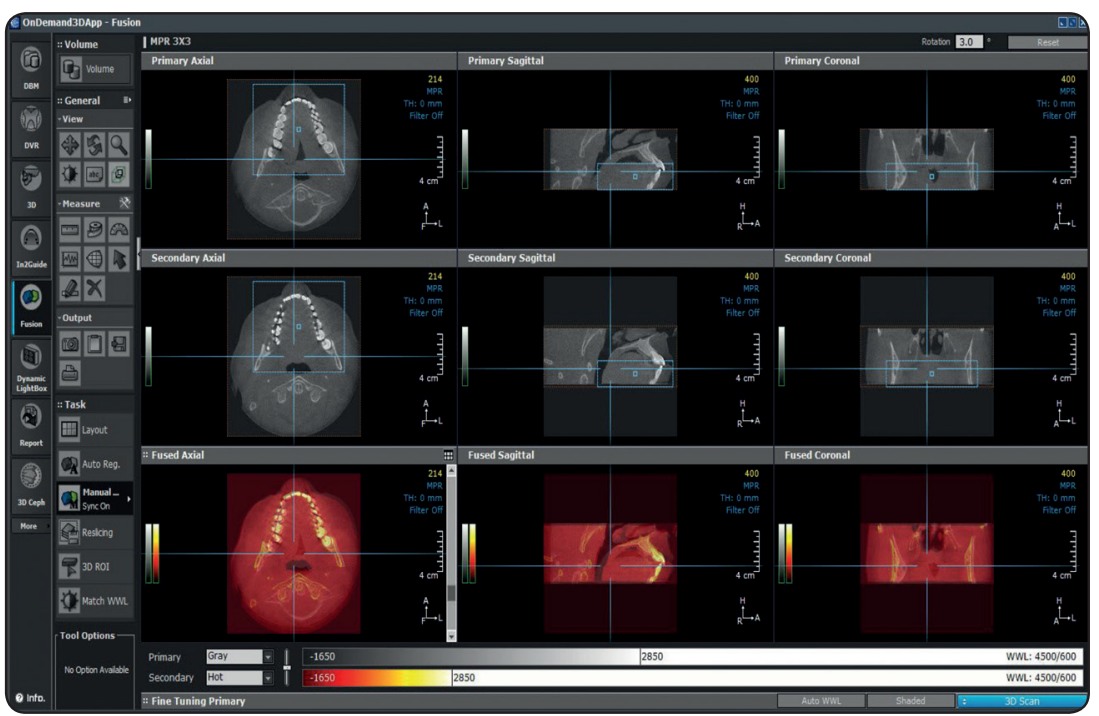

Fig. (1): Using the Fusion module for registration of two CBCT images (postoperative and six months) 
the tooth under investigation (Fig 2). On the coronal window, at the same selected ROI, the sagittal plane was oriented parallel to the long axis of the tooth. The resultant sagittal image was used for measurement of bone level (Fig. 1). We measured the distance between the CEJ and the DBL both mesially and distally for each tooth involved using the measure tool. The previously described method was repeated for all ROI(s) for each patient. All measurements were repeated after two weeks by the same observer to assess intra-observer reliability. Data were tabulated and statistically analysed

\section{Statistical Analysis}

Numerical data were explored for normality by checking the distribution of data and using tests of normality (Kolmogorov-Smirnov and Shapiro-Wilk tests). Bone level data showed normal (parametric) distribution while bone gain data showed nonnormal (non-parametric) distribution. Data were presented as mean, standard deviation (SD), median and range values. Repeated measures ANOVA test was used to study the changes in bone level by time within each side. Bonferroni's post-hoc test was used for pair-wise comparisons. Wilcoxon signedrank test was used to compare between bone gain in
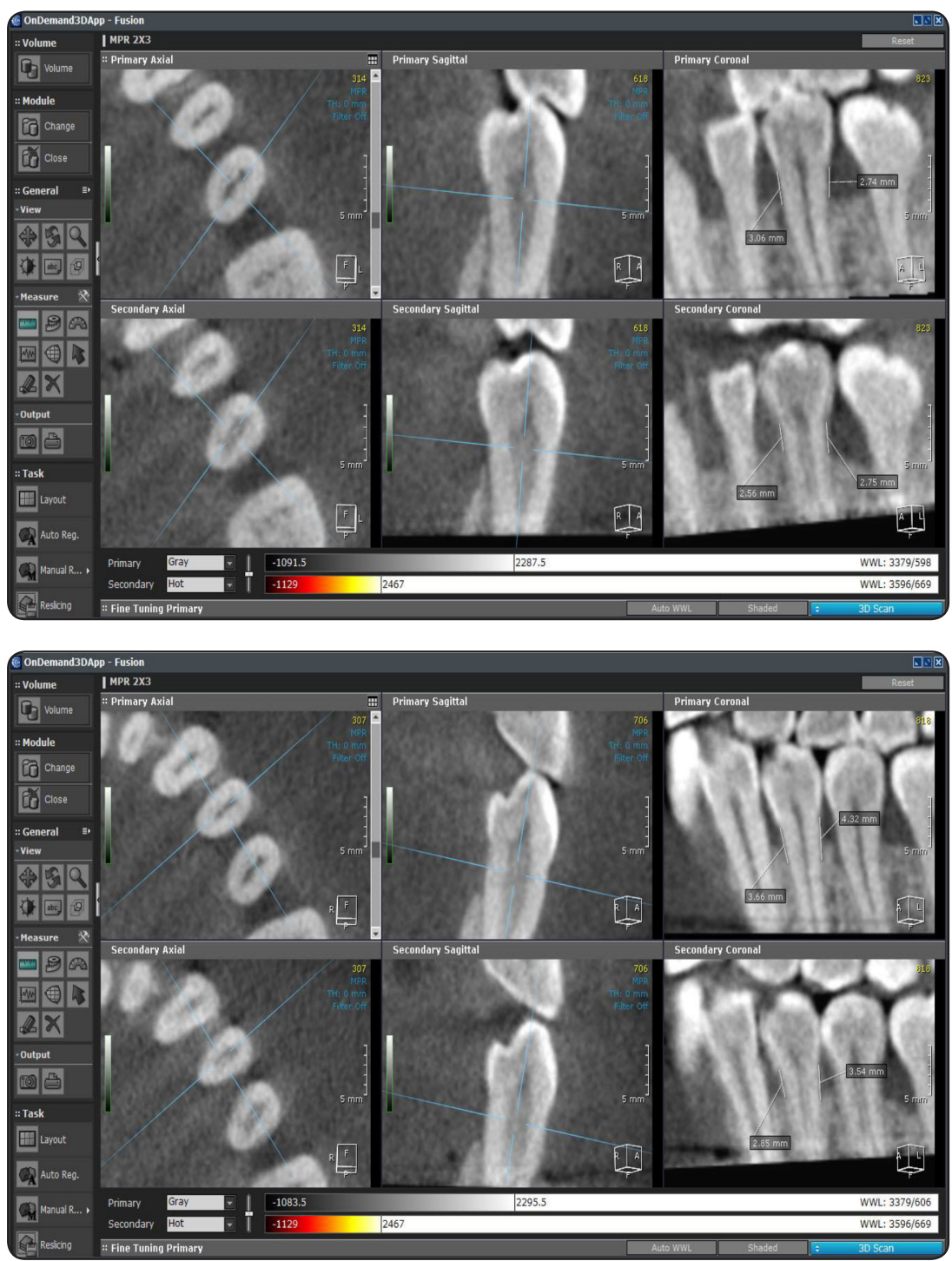

Fig (2): Using the linear measurements tool at the same area in postoperative and six months CBCT images allows accurate calculation of bony changes (PM group)
Fig (3): Using the linear measurements tool at the same area in postoperative and six months CBCT images allows accurate calculation of bony changes (OM group) 
the right and left sides. The significance level was set at $\mathrm{P} \leq 0.05$. Statistical analysis was performed with IBM SPSS Statistics for Windows, Version 23.0. Armonk, NY: IBM Corp.

\section{RESULTS}

\section{Radiographic results}

\section{Bone level changes within each group}

As regards the PM Group; there was a statistically significant increase in mean bone level at the M1P, D1P, M2P, D2P, MR1M and DR1M after 6 months $(P$-value $<0.001$, Effect size $=0.938),(P$-value $=0.002$, Effect size $=0.877),(P$-value $=0.001$, Effect size $=0.907),(P$-value $=0.031$, Effect size $=0.641),(P$-value $=0.005$, Effect size $=0.947)$ and $(P$-value $<0.001$, Effect size $=0.954)$, respectively.
As regards the total change regardless of region; there was a statistically significant increase in mean bone level after 6 months $(P$-value $<0.001$, Effect size $=0.823$ ).

While for the OM Group; there was a statistically significant increase in mean bone level at the M1P, D1P and D2P after 6 months $(P$-value $=0.002$, Effect size $=0.876),(P$-value $=0.032$, Effect size $=$ $0.633)$ and $(P$-value $=0.026$, Effect size $=0.663)$, respectively. At M2P, MR1M and DR1M regions; there was no statistically significant change in mean bone level after 6 months $(P$-value $=0.067$, Effect size $=0.521),(P$-value $=0.089$, Effect size $=0.672)$ and $(P$-value $=0.167$, Effect size $=0.343)$, respectively. As regards the total change regardless of region; there was a statistically significant increase in mean bone level after 6 months $(P$-value $<0.001$, Effect size $=0.585$ ).

TABLE (1) : Descriptive statistics and results of repeated measures ANOVA test for comparison between bone levels $(\mathrm{mm})$ post-operatively and after 6 months within each group

\begin{tabular}{|c|c|c|c|c|c|c|c|}
\hline \multirow{2}{*}{ Side } & \multirow{2}{*}{ Region } & \multicolumn{2}{|c|}{ Post-operative } & \multicolumn{2}{|c|}{6 months } & \multirow{2}{*}{$P$-value } & \multirow{2}{*}{$\begin{array}{c}\text { Effect size (Partial } \\
\text { Eta Squared) }\end{array}$} \\
\hline & & Mean & SD & Mean & SD & & \\
\hline \multirow{7}{*}{ PM Group } & M1P & 3.37 & 0.8 & 2.83 & 0.74 & $<0.001 *$ & 0.938 \\
\hline & D1P & 3.48 & 0.51 & 3.15 & 0.57 & $0.002 *$ & 0.877 \\
\hline & M2P & 3.23 & 0.64 & 2.77 & 0.67 & $0.001 *$ & 0.907 \\
\hline & D2P & 3.08 & 0.54 & 2.92 & 0.51 & $0.031 *$ & 0.641 \\
\hline & MR1M & 3.7 & 0.42 & 3.4 & 0.39 & $0.005 *$ & 0.947 \\
\hline & DR1M & 3.97 & 0.43 & 3.48 & 0.48 & $<0.001 *$ & 0.954 \\
\hline & Total & 3.46 & 0.61 & 3.07 & 0.6 & $<0.001 *$ & 0.823 \\
\hline \multirow{7}{*}{ OM Group } & M1P & 2.98 & 0.52 & 2.4 & 0.55 & $0.002 *$ & 0.876 \\
\hline & D1P & 3.25 & 0.67 & 2.93 & 0.42 & $0.032 *$ & 0.633 \\
\hline & M2P & 3.15 & 0.52 & 2.98 & 0.5 & 0.067 & 0.521 \\
\hline & D2P & 3.47 & 0.47 & 3.08 & 0.19 & $0.026 *$ & 0.663 \\
\hline & MR1M & 3.3 & 0.63 & 3.03 & 0.44 & 0.089 & 0.672 \\
\hline & DR1M & 2.92 & 0.63 & 2.72 & 0.37 & 0.167 & 0.343 \\
\hline & Total & 3.17 & 0.56 & 2.85 & 0.46 & $<0.001 *$ & 0.585 \\
\hline
\end{tabular}


Comparison between bone level changes in the two groups

There was no statistically significant difference between changes in mean bone level in the two groups at the M1P, D1P, D2P, MR1M and DR1M after 6 months $(\mathrm{P}$-value $=0.673$, Effect size $=0.350)$, $(\mathrm{P}$-value $=0.498$, Effect size $=0.575),(\mathrm{P}$-value $=$ 0.144$, Effect size $=1.486),(\mathrm{P}$-value $=0.713$, Effect size $=0.304)$ and $(\mathrm{P}$-value $=0.058$, Effect size $=$ $2.448)$, respectively except at the $\mathrm{M} 2 \mathrm{P}$ region as the right side showed statistically significant increase in mean bone gain than left side (P-value $=0.043$, Effect size $=2.930$ ). As regards the total changes in bone level regardless of region; there was no statistically significant difference between the two sides $(\mathrm{P}$-value $=0.265$, Effect size $=1.021)$.

\section{Clinical results}

Comparison between the two studied periods according to plaque index

There was no-statistically significant differ- ence between the two groups in mean plaque index (Table 3)

\section{Comparison between the two studied periods ac- cording to gingival index}

There was no-statistically significant difference between the two groups in mean gingival index (Table 3)

\section{Comparison between the two studied groups ac-} cording to probing depth:

PM Group showed a statistically significant higher decrease in mean probing depth compared to OM Group (Table 3)

\section{Comparison between the two studied groups ac- cording to clinical attachment loss}

There was non-statistically significant difference between the two groups in mean clinical attachment levels at baseline nor at 6 months. (Table 3)

TABLE (2): Descriptive statistics and results of Wilcoxon signed-rank test for comparison between bone loss (mm) in the two groups

\begin{tabular}{|c|c|c|c|c|c|c|c|c|c|c|}
\hline \multirow{2}{*}{ Region } & \multicolumn{4}{|c|}{ PM Group } & \multicolumn{4}{|c|}{ OM Group } & \multirow{2}{*}{ P-value } & \multirow{2}{*}{$\begin{array}{l}\text { Effect } \\
\text { size (d) }\end{array}$} \\
\hline & Mean & $\mathrm{SD}$ & Median & Range & Mean & SD & Median & Range & & \\
\hline M1P & 0.53 & 0.15 & 0.6 & $0.3-0.7$ & 0.58 & 0.24 & 0.6 & $0.3-0.8$ & 0.673 & 0.350 \\
\hline D1P & 0.33 & 0.14 & 0.3 & $0.2-0.5$ & 0.32 & 0.26 & 0.3 & $0.2-0.5$ & 0.498 & 0.575 \\
\hline M2P & 0.47 & 0.16 & 0.45 & $0.3-0.7$ & 0.17 & 0.18 & 0.45 & $0.3-0.7$ & $0.043 *$ & 2.930 \\
\hline $\mathrm{D} 2 \mathrm{P}$ & 0.17 & 0.14 & 0.2 & $0-0.3$ & 0.38 & 0.3 & 0.2 & $0-0.3$ & 0.144 & 1.486 \\
\hline MR1M & 0.3 & 0.08 & 0.3 & $0.2-0.4$ & 0.28 & 0.22 & 0.3 & $0.2-0.4$ & 0.713 & 0.304 \\
\hline DR1M & 0.48 & 0.12 & 0.45 & 0.4-0.7 & 0.2 & 0.3 & 0.45 & $0.4-0.7$ & 0.058 & 2.448 \\
\hline Total & 0.39 & 0.18 & 0.4 & $0-0.7$ & 0.32 & 0.28 & 0.3 & $0-0.8$ & 0.265 & 1.021 \\
\hline
\end{tabular}

*: Significant at $P \leq 0.05$ 
TABLE (3): Results of Comparison between zero and six months clinical parameters

\begin{tabular}{|c|c|c|c|c|c|c|}
\hline & \multicolumn{2}{|c|}{ PM Group } & \multicolumn{2}{|c|}{ OM Group } & \multirow[t]{2}{*}{$\mathrm{U}$} & \multirow[t]{2}{*}{$\mathrm{p}$} \\
\hline & Mean & $\pm \mathrm{SD}$ & Mean & $\pm \mathrm{SD}$ & & \\
\hline \multicolumn{7}{|l|}{ Plaque Index } \\
\hline Base line & 0.0 & 0.0 & 0.0 & 0.0 & 60.50 & 1.000 \\
\hline 6 Months & 0.27 & 0.47 & 0.27 & 0.47 & 60.50 & 1.000 \\
\hline \multicolumn{7}{|l|}{ Gingival Index } \\
\hline Baseline & 0.55 & 0.52 & 0.55 & 0.52 & 60.50 & 1.000 \\
\hline 6 Months & 0.45 & 0.52 & 0.45 & 0.52 & 60.50 & 1.000 \\
\hline \multicolumn{7}{|l|}{ Probing depth } \\
\hline Baseline & 5.27 & 0.47 & 5.91 & 0.70 & $2.506^{*}$ & 0.221 \\
\hline 6 Months & 3.64 & 0.81 & 5.18 & 0.72 & $4.742^{*}$ & $<0.001^{*}$ \\
\hline \multicolumn{7}{|c|}{ Clinical attachment loss } \\
\hline Baseline & 3.36 & 0.67 & 3.23 & 0.75 & 0.447 & 0.660 \\
\hline 6 Months & 2.27 & 0.47 & 2.77 & 0.56 & $2.264^{*}$ & $0.035^{*}$ \\
\hline
\end{tabular}

\section{DISCUSSION}

The idea of complete periodontal regeneration is considered to be unrealistic in most clinical situation and that is due to the interplay of many cells and mediators which require certain coordination and integration. ${ }^{(60)}$ Melcher ${ }^{(61)}$ first produced the idea that the type of cells to repopulate the root surface after regenerative techniques will determine the nature of the attachment that will take place, and later Nyman and Karring ${ }^{(62)}$ proved that selective cell infiltration can affect the type of cells to occupy the wound area.

Membranes serve the purpose of excluding unwanted epithelial cells while providing space for PDL cells, bone cells and/or cementoblasts. (63) Recent evidence has shown the capacity of gingival fibroblasts to express mRNA for alkaline phosphatase (ALP) and bone morphogenic proteins 2 and 4 which can be directed to hard tissue formation. ${ }^{(64)}$ The same for gingival mesenchymal stem cells (GMSCs) which are capable of expressing mRNA of bone specific markers such as ALP, osteonectin, oesteopontin when exposed to an osteogenic differentiation medium. ${ }^{(65)}$ Moreover, when incubated with tumor necrosis factor alpha and Interleukin 1 Beta, GMSCs showed few inflammatory related changes. ${ }^{(66)}$ In addition, the oral periosteum is an unlimited source of cells with a great capacity for expansion, stemness and differentiation potential towards osteoblastic lineage without the need for osteogenic medium. ${ }^{(67)}$

Based on the above, in this study we compared the use of perforated collagen membranes which would potentially allow gingival CT and periosteal cells to repopulate the root surface with the traditional occlusive ones that could deprive the defect from an important source of cells required for regeneration. In each of these two groups, as it is essential for the bone substitute to have a totally interconnected porous design in order to be easily invaded by cells and blood vessels, ${ }^{(68)}$ the membranes were combined with nano-micro-sized hydroxyapatite composite graft. The rationale for the use of the composite graft is to take advantage 
of the higher performance nano-sized HA with its greater surface-area-to volume ratio as well as micro-sized xenograft to reduce the direct systemic dissemination or phagocytosis of the nanosized particles and thus increasing its availability locally in the periodontal defect. ${ }^{(43)}$

The traditional methods for evaluation of periodontal regeneration include clinical measurements, radiographic analysis and histology, however, the correlation between clinical measurements and histology in relation to regeneration is not as reliable as histologic and radiographic analysis. ${ }^{(69)}$

Moreover, nowadays with the advent of new technologies that are non-invasive, more objective and free from bias, are of potential benefit and hence, the use of Cone-beam Computed Tomography in this study. CBCT examination was performed immediately post-operatively and 6 months later, not only to assess the regenerative capacity of the combination of materials used but to assess the stability of the bone levels and the degree of bone fill after complete remodelling. In that regard, we based our clinical and radiographic examination timing on the finding of two systematic reviews, ${ }^{(70)}$ a meta analysis ${ }^{(71)}$ that concluded that GTR was far more efficient than open flap debridement regarding gain of clinical attachment and probing depth reduction when treating intrabony defects. They also concluded that there was little value in conducting future research repeating simple, small efficacy studies, but rather focus on large observational studies and outcomes relevant to the patients. Stemming from the concept of patientcentred outcomes, we opted to limit our timing of radiographic examination to an immediate postoperative and six months later in order to evaluate the long-term stability of bone fill.

The results of our study showed no significant difference between the two groups regarding the difference between the baseline and 6 months-time periods regarding the gingival index and plaque index, however they remained below 0.5 , which indicated that patients with oral hygiene measures. The PM group showed a significant reduction in mean PD compared to the OM group, these results support the hypothesis that the PM had a positive effect on clinical measurements. Those results are also in accordance with Gamal and Iacono ${ }^{(55)}$ who showed a significant PD reduction at 6 and 9 months period in favour of the perforated membranes when compared with occlusive ones.

Regarding the gain in clinical attachment, there was no significant difference between the two groups, that was in accordance with the randomized controlled trial that was conducted by Górski et al. ${ }^{(72)}$ that compared the clinical and radiographic outcome of the use of modified perforated collagen membrane to a standard one and reported no statistical significant difference between the two groups regarding the improvement in all clinical parameters. However, this was in contradiction with Gamal and Iacono ${ }^{(55)}$ who reported a statistically significant superior outcome in favour of the perforated membrane. This can be attributed to their use of collagen membrane as the sole regenerative material whereas in our study the use of combined regenerative materials (collagen membrane and the composite/nano-micro-sized graft) in both sites which may have resulted in attaining the maximum gain in attachment in both groups.

As regards to the bone level changes within each group, in the PM Group, there was a statistically significant decrease in mean bone level after 6 months $(P$-value $<0.001$, Effect size $=0.765)$. While at the left side, there was a statistically significant decrease in mean bone level after 6 months ( $P$-value $<0.001$, Effect size $=0.262)$. This can be attributed to the normal remodeling process that takes place during this time period based on the principle of resorption/substitution of osteointegrated biomaterial with new-bone. ${ }^{(72)}$

Upon comparing bone loss in the two groups, there was no statistically significant difference in the mean bone changes $(P$-value $=0.237$, Effect 
size $=1.101)$. To our knowledge, this is the first attempt to compare bone changes 6 months postoperatively to immediate post-operative one. Our results entail that there was no superiority to the use of the PM as compared to the OM regarding bone changes 6 months post-operatively, as both resulted in similar bone changes. These results are in accordance with Górski et al. ${ }^{(72)}$ who compared the use of xenogenic graft plus modified perforated membrane to xenogenic graft plus conventional occlusive membrane and reported no statistically significant difference between the two groups at the six months outcome duration, however at the 12-months duration, the modified perforated membrane group showed a significant improvement regarding the defect fill compared to the six-month time point.

\section{CONCLUSION}

Our study showed no statistical significant difference between the perforated membranes versus the occlusive membrane regarding defect bone fill at 6 months duration.

\section{REFERENCES}

1. Papapanou PN, Sanz M, et al. Periodontitis: Consensus report of workgroup 2 of the 2017 World Workshop on the Classification of Periodontal and Peri-Implant Diseases and Conditions. J Clin Periodontol. 2018;45(Suppl 20):S162-S170.

2. Caton J, Armitage G, Berglundh Chapple I, Jepsen S, Kornman K, Mealey B, Papapanou P, Sanz M, Tonetti M. Anew classification scheme for periodontal and peri-implant diseases and conditions-introduction and key changes from the 1999 classification. J. Periodontol. 2018; 89 (Suppl. 1), S1-S8.

3. Herrera D, Retamal-Valdes B, Alonso B, Feres M. Acute periodontal lesions (periodontal abscesses and necrotizing periodontal diseases) and endo-periodontal lesions. J Clin Periodontol. 2018;45(Suppl 20):S78-S94.

4. Albandar JM, Susin C, Hughes FJ. Manifestations of systemic diseases and conditions that affect the periodontal attachment apparatus: case definitions and diagnostic considerations. J Clin Periodontol. 2018;45(Suppl 20):S171-S189.
5. Needleman I, Garcia R, Gkranias N, et al. Mean annual attachment, bone level and tooth loss: A systematic review. J Clin Periodontol. 2018;45(Suppl 20):S112-S129.

6. Fine DH, Patil AG, Loos BG. Classification and diagnosis of aggressive periodontitis. J Clin Periodontol. 2018;45(Suppl 20): S95-S111.

7. Billings M, Holtfreter B, Papapanou PN, Mitnik GL, Kocher T, Dye BA. Age-dependent distribution of periodontitis in two countries: findings from NHANES 2009 to 2014 and SHIP-TREND 2008 to 2012. J Clin Periodontol. 2018;45(Suppl 20):S130-S148.

8. Tonetti MS, Greenwell H, Kornman KS. Staging and grading of periodontitis: Framework and proposal of a new classification and case definition. J Clin Periodontol. 2018;45(Suppl 20):S149-S161.

9. Matuliene G, Pjetursson BE, Salvi GE, Schmidlin K, Brägger U, Zwahlen M, Lang NP. Influence of residual pockets on progression of periodontitis and tooth loss: results after 11 years of maintenance. J Clin Periodontol 2008: 35: 685- 695.

10. Papapanou PN, Tonetti MS. Diagnosis and epidemiology of periodontal osseous lesions. Periodontol 2000 2000: 22:8-21.

11. Caton JG, Greenstein G. Factors related to periodontal regeneration. Periodontol 2000 1993: 1: 9-15.

12. Sculean A, Nikolidakis D, Nikou G, Ivanovic A, Chapple ILC \& Stavropoulos A. Biomaterials for promoting periodontal regeneration in human intrabony defects: a systematic review. Periodontol 2000 2015:68: 182-216.

13. Cortellini P, Tonetti MS. Focus on intrabony defects: guided tissue regeneration. Periodontol 2000 2000: 22: 104-132.

14. Cortellini P, Tonetti MS. Long-term tooth survival following regenerative treatment of intrabony defects. J Periodontol 2004: 75: 672-678.

15. Kao RT, Nares S, Reynolds MA. Periodontal regeneration - intrabony defects: a systematic review from the AAP regeneration workshop. J Periodontol 2015: 86(2 Suppl): S77-S104.

16. Mariotti A. Efficacy of chemical root surface modifiers in the treatment of periodontal disease. A systematic review. Ann Periodontol 2003: 8: 205-226.

17. Miron RJ, Guillemette V, Zhang Y, Chandad F, Sculean A. Enamel matrix derivative in combination with bone grafts: A review of the literature. Quintessence Int 2014: 45: 475- 487 . 
18. Sculean AAR, Miron R, Salvi GE, Bosshardt DD. Enamel Matrix Proteins and Periodontal Wound Healing and Regeneration. Clinic Adv Periodontics 2011; 1: 101-117.

19. Stavropoulos A, Windisch P, Gera I, Capsius B, Sculean A, Wikesjo UM. A phase IIa randomized controlled clinical and histological pilot study evaluating rhGDF-5/beta-TCP for periodontal regeneration. J Clin Periodontol 2011: 38: 1044-1054.

20. Reynolds MA, Aichelmann-Reidy ME, Branch-Mays GL, Gunsolley JC. The efficacy of bone replacement grafts in the treatment of periodontal osseous defects. A systematic review. Ann Periodontol 2003;8: 227-265.

21. Needleman I, Tucker R, Giedrys-Leeper E, Worthington H. Guided tissue regeneration for periodontal intrabony defects - A Cochrane Systematic Review. Periodontol 2000 2005;37:106-123.

22. Koop R, Merheb J, Quirynen M. Periodontal regeneration with enamel matrix derivative in reconstructive periodontal therapy: A systematic review. J Periodontol 2012;83:707-720.

23. Sculean A, Nikolidakis D, Schwarz F. Regeneration of periodontal tissues: Combinations of barrier membranes and grafting materials-Biological foundation and preclinical evidence: A systematic review. J Clin Periodontol 2008;35(Suppl. 8):106-116.

24. Stahl SS, Froum SJ, Tarnow D. Human clinical and histologic responses to the placement of HTR polymer particles in 11 intrabony lesions. J Periodontol 1990;61:269-274.

25. Nevins ML, Camelo M, Nevins M, et al. Human histologic evaluation of bioactive ceramic in the treatment of periodontal osseous defects. Int J Periodontics Restorative Dent 2000;20:458-467.

26. Sutha S, Kavitha K, Karunakaran G, Rajendran V. Invitro bioactivity, biocorrosion and antibacterial activity of silicon integrated hydroxyapatite/chitosan composite coating on 316 L stainless steel implants. Mater Sci Eng C Mater Biol Appl 2013;33:4046-4054.

27. Alves Cardoso D, Jansen JA, Leeuwenburgh SC. Synthesis and application of nanostructured calcium phosphate ceramics for bone regeneration. J Biomed Mater Res B Appl Biomater 2012;100:2316-2326.

28. Tamai N, Myoui A, Tomita T, et al. Novel hydroxyapatite ceramics with an interconnective porous structure exhibit superior osteoconduction in vivo. J Biomed Mater Res 2002;59:110-117.
29. Kalita SJ, Bhardwaj A, Bhatt HA. Nanocrystalline calcium phosphate ceramics in biomedical engineering. Mater Sci Eng C 2007; 27:441-449.

30. Sanosh KP, Chu M-C, Brishnan A, Kim TN, Cho S-J. Preparation and characterization of nano-hydroxyapatite powder using sol-gel technique. Bull Mater Sci 2012;32: 465-470.

31. Murugan R, Ramakrishna S. Coupling of therapeutic molecules onto surface modified coralline hydroxyapatite. Biomaterials 2004;25:3073-3080.

32. Doherty SA, Hile DD, Wise DL, Ying JY, Sonis ST, Trantolo DJ. Nanoparticulate hydroxyapatite enhances the bioactivity of a resorbable bone graft. MRS Proceedings 2002; 735: C6.4. doi:dx.doi.org/10.1557/PROC-735-C6.4.

33. Kasaj A, R€ohrig B, Zafiropoulos G-G, et al. Clinical evaluation of nanocrystalline hydroxyapatite paste in the treatment of human periodontal bony defects $-\mathrm{A}$ randomized controlled clinical trial: 6-month results. J Periodontol. 2008; 79(3):394-400.

34. Heinz B, Kasaj A, Teich M, Jepsen S. Clinical effects of nanocrystalline hydroxyapatite paste in the treatment of intrabony periodontal defects: A randomized controlled clinical study. Clin Oral Investig 2010;14: 525-531.

35. Kanaya S, Nemoto E, Sakisaka Y, et al. Calcium-mediated increased expression of fibroblast growth factor- 2 acts through NF-kappaB and PGE2/EP4 receptor signaling pathways in cementoblasts. Bone. 2013;56(2):398-405.

36. Wang J, Wang L and Fan Y. Adverse Biological Effect of $\mathrm{TiO} 2$ and Hydroxyapatite

37. Nanoparticles Used in Bone Repair and Replacement. Int. J. Mol. Sci. 2016;17(6),798- 511.

38. Gamble W. Atherosclerosis: The carbonic anhydrase, carbon dioxide, calcium concerted theory. J Theor Biol 2006;239:16-21.

39. Uskokoviç V. Surface charge effects involved in the control of stability of sols comprising uniform cholesterol particles. Mater Manuf Process 2008;23:620-623.

40. Zhou G, Li Y, Xiao W, et al. Synthesis, characterization, and antibacterial activities of a novel nanohydroxyapatite/ zinc oxide complex. J Biomed Mater Res A 2008;85:929937.

41. Motskin M, Wright DM, Muller K, et al. Hydroxyapatite nano and microparticles: Correlation of particle prop- 
erties with cytotoxicity and biostability. Biomaterials 2009;30:3307-3317.

42. Scheel J, Weimans S, Thiemann A, Heisler E, Hermann M. Exposure of the murine RAW 264.7 macrophage cell line to hydroxyapatite dispersions of various composition and morphology: Assessment of cytotoxicity, activation and stress response. Toxicol In Vitro 2009;23:531-538.

43. Gamal AY and Iacono VJ. Mixed nano/micro-sized calcium phosphate composite and EDTA root surface etching improve availability of graft material in intrabony defects: An in vivo scanning electron microscopy evaluation. J Periodontol 2013;84:1730-1739.

44. Athanasiou VT, Papachristou DJ, Panagopoulos A, Saridis A, Scopa CD, Megas P. Histological comparison of autograft, allograft-DBM, xenograft, and synthetic grafts in a trabecular bone defect: An experimental study in rabbits. Medical Science Monitor 2010;16:BR24-BR31.

45. Vishwakarma A, Sharpe P, Shi S, Ramalingam M. Stem cell biology and tissue engineering in dental sciences. London, UK: Academic Press. 2014.

46. Ceccarelli G, Presta R, Benedetti L, Cusella De Angelis MG, Lupi SM, Rodriguez YBR. Emerging perspectives in scaffold for tissue engineering in oral surgery. Stem Cells Int., 2017;10:1-11.

47. Pertici G, Rossi F, Casalini T, Perale G. Composite polymer-coated mineral grafts for bone regeneration: Material characterisation and model study. Ann Maxillofac Surg. 2014;2(1):4-11.

48. Stacchi C, Lombardi T, Ottonelli R, Berton F, Perinetti G, Traini T. (2018). New bone formation after transcrestal sinus floor elevation was influenced by sinus cavity dimensions: A prospective histologic and histomorphometric study. Clinical Oral Implants Research. 2018;29:465-479.

49. Roato I, Belisario DC, Compagno M, Verderio L, Sighinolfi A, Mussano F, Genova T, Veneziano F, Pertici G, Perale G, Ferracini, R. Adipose-derived stromal vascular fraction/xenohybrid bone scaffold: An alternative source for bone regeneration. Stem Cells Int. 2018, 4126379.

50. Melcher AH. On the repair potential of periodontal tissues. J Periodontol 1976;47:256-260.

51. Iglhaut J, Aukhil I, Simpson DM, Johnston MC, Koch G. Progenitor cell kinetics during guided tissue regeneration in experimental periodontal wounds. J Periodontal Res 1988;23:107-117.
52. Mitrano TI, Grob MS, Carrión F, et al. Culture and characterization of mesenchymal stem cells from human gingival tissue. J Periodontol 2010;81:917-925.

53. Tomar GB, Srivastava RK, Gupta N, et al. Human gingiva-derived mesenchymal stem cells are superior to bone marrow-derived mesenchymal stem cells for cell therapy in regenerative medicine. Biochem Biophys Res Commun 2010;393:377-383.

54. Tang L, Li N, Xie H, Jin Y. Characterization of mesenchymal stem cells from human normal and hyperplastic gingiva. J Cell Physiol 2011;226:832-842.

55. Gamal AY, Iacono VJ. Enhancing guided tissue regeneration of periodontal defects by using a novel perforated barrier membrane. J Periodontol 2013;84:905-913.

56. Kerr D, Millard H. Oral diagnosis, second edition. C.V. Mosby Company, Saint Louis; Pp. 17, 1965.

57. Silness J, Loe H. Periodontal disease in pregnancy. Acta odont. scand. 1964;22: 121-135.

58. Takei H, Carranza F. Clinical Diagnosis. In Carranza's Clinical Periodontology (2012).(11th ed., Vol. 1, pp. 349353). St. Louis, Missouri: Saunders, an imprint of Elsevier.

59. Assiri H, Dawasaz AA, Asiri Z. Cone beam computed tomography $(\mathrm{CBCT})$ in periodontal diseases: a Systematic review based on the efficacy model. BMC Oral Health 2020; 20, 191-205.

60. Bartold PM Group C. Initiator paper. Periodontal regeneration-fact or fiction. J Int Acad Periodontol 2015;17: 37-49.

61. Melcher AH. On the repair potential of periodontal tissues. J. Periodontol. 1976; 47, 256-260.

62. Nyman S, Lindhe J, Karring T, Rylander H. New attachment following surgical treatment of human periodontal disease. J. Clin. Periodontol. 1982; 9, 290-296.

63. Cortellini P, Tonetti M. Clinical concepts for regenerative therapy in intrabony defects. Periodontology 2000 2015; $68,282-307$.

64. Ivanoceski S, Li H, Haase H, Bartold P. Expression of bone associated macromolecules by gingival and periodontal ligament fibroblasts. J Periodontal Res 2001; 36(3): 131-141.

65. Fawzy El-Sayed KM, Dörfer CE. Gingival mesenchymal stem/progenitor cells: a unique tissue engineering gem. Stem Cells Int 2016; 7154327:1-16. 
66. Santamaria S, Sanchez N, Sanz M, Garcia-Sanz JA. Comparison of periodontal ligament and gingiva-derived mesenchymal stem cells for regenerative therapies. Clin Oral Invest 2017;21(4):1095-1102.

67. Ceccarelli G, Graziano A, Benedetti L, Imbriani M, Romano F, Ferrarotti F, Aimetti M, Cusella de Angelis GM. Osteogenic potential of human oral-periosteal cells (PCs) isolated from different oral origin: an in vitro study. J Cell Physiol 2016;231(3):607-612

68. Sanosh KP, Chu M-C, Brishnan A, Kim TN, Cho S-J. Preparation and characterization of nano-hydroxyapatite powder using sol-gel technique. Bull Mater Sci 2012;32:465-470

69. Bhavsar AK, Parween S, Karthikeyan BV, Prabhuji MLV.
Critical Issues in Periodontal Regeneration - A Review. J Oral Health Dent 2018;2: 204-212

70. Murphy KG, Gunsolley JC. Guided tissue regeneration for the treatment of periodontal intrabony and furcation defects. A systematic review. Ann. Periodontol. 2003;8, 266-302

71. Needleman IG, Worthington HV, Giedrys-Leeper E, Tucker RJ. Guided tissue regeneration for periodontal infra-bony defects. Chocrane Database Syst. Rev. 2006;19, CD001724.

72. Tonelli P, Duvina M, Barbato L, Biondi E, Nuti N, Brancato L, Rose GD. Bone regeneration in dentistry. Clin Cases Miner Bone Metab. 2011;8(3):24-28. 